\title{
Hedging Effectiveness in Energy Market during Economic Crisis : Better Way to Integration
}

\author{
Aristeidis Samitas \\ University of the Aegean \\ Ioannis Tsakalos \\ University of the Aegean \\ Nikolaos Eriotis \\ University of Athens
}

\begin{abstract}
This paper investigates hedging and risk management options in the energy sector. Energy firms tend to adopt risk management tools in order to cover their financial exposure. Taking into consideration that current crisis has a significant effect on their value; we check whether energy firms actually have better output when they use hedging tools. In order to measure the effectiveness of this strategy in the energy industry, we adopt Tobin's $Q$ methodology. The sample of this study consists energy firms on a worldwide basis. The empirical evidence of this research confirms that energy firms may avoid huge economic problems when they adopt risk management methods. It is better enery market integration.
\end{abstract}

- JEL Classification: G14, G15

- Keywords: Energy, Tobin's Q, Hedging Effectiveness, Financial Crisis

\footnotetext{
*Corresponding address: Aristeidis Samitas: Department of Business Administration, University of the Aegean, 8 Michalon Str., Chios 82100, Greece, Tel: +302271035158, Fax: +302271035099, E-mail: a.samitas@ba.aegean.gr. / Ioannis Tsakalos: Department of Business Administration, University of the Aegean, 8 Michalon Str., Chios 82100, Greece, Tel: +302271035158, Fax: +302271035099, E-mail: i.tsakalos@ba.aegean.gr. / Nikolaos Eriotis: Department of Economics, University of Athens, 5 Stadiou Str., Athens 10562, Greece, Tel: +302103689400, Fax:+302103689410, E-mail: n.eriot@econ.uoa.gr. (C2011-Center for Economic Integration, Sejong Institution, Sejong University, All Rights Reserved.
} 


\section{Introduction}

The last few years, world economy became extremely volatile and "subprime" loans pushed economy to its worst recession in the last seventy years. The markets' drop replaced firms' high profits, investments and development. Unfortunately, the end of this recession is still unknown, but we are obviously able to see its consequences already. Investors cannot avoid the negative results that this economic crisis has on their firms' value. Even though many of them had absolutely strong structure and their financial statements were very good, low demand and market uncertainty lead to lower sales and therefore lower profits. Firms which invested in order to get back higher profits came against a very bad economic environment and financial crisis hit their investment.

Usually, energy market's liberalisation is followed by high competition and aggressive investments, since state owned companies do not easily expand their activities and operations in other potentially niece markets or even other countries. Nowadays a lot of energy firms from the European Union, US and also other countries are trying to develop rapidly in order to find cheaper and environmental friendly energy solutions. EU's economic integration needs to be followed by all sectors including energy and it is not simply a common monetary policy.

Becker-Blease et al. (2007) examined if utilities that sought to diversify into new geographic areas or new power markets (natural gas), perform differently from those that remain focused on their existing power sources and areas. New markets and areas mean big investments and investments bring them uncertainty.

Firms' development depends on their investment policy and the risk they want to adopt. Some of them grow rapidly because they take big risks and others develop steadily, step by step. Within the last decade, many firms tried to avoid taking big risks due to high competition and market's volatility. The most common way for them to evolve without having problems was to hedge their risks. Thus, they tried to manage the unverifiable variables which could cause them many financial or operational consequences.

Energy firms can use a variety of risk management tools in order to secure their earnings and stabilize their costs. The main instruments that energy firms use are futures and swaps. Futures are traded in NYMEX, TOCOM and the Intercontinental Exchange. On the other hand, swaps are traded between the interested parties, which must be reliable in order to avoid any non-performance issues. Both parties in these cases take the credit risk for their counterpart. 
Limited energy derivatives products are an obstacle for the efficiency of these tools in specific energy areas. Complicated energy markets with low contract volume, such as jet fuel and marine fuel markets, together with the lack of energy derivatives with precise equivalence to them, are parameters which slow down the wide development of hedging. Market liberation though created an on growing need for such products which assisted on their evolvement.

Finally, the volume of the hedging contracts is directly related with their efficiency. There are several key goals associated with hedging effectiveness such as, (1) energy derivatives help firms to avoid market risk exposure; (2) risk management gives a premium to firms' financial value; and (3) energy firms may keep growing during financial crises.

The purpose of this paper is to examine and prove whether energy derivatives and risk management can add financial value to energy firms and secure their position during turbulent economic periods. The objective though, is to quantify the effect of risk management on firms' economic value. Risk management's impact may differ and the result depends on various factors. However, financial crashes are the most suitable periods to understand the meaning of hedging and its subscription on firms' financial stability. High volatile periods bring researchers in front of a clear picture and safer conclusions.

The rest of the paper is structured as below. The next section refers to the literature review. Section III outlines the data and methodology used and section IV provides the empirical results. Finally, paper concludes by section $\mathrm{V}$ which refers to study's implications.

\section{Literature Review}

Energy industry becomes more and more interesting due to its incredible development and the substantial increase in its products' demand. Financial crisis hit energy, like every other sector, and unstable market conditions caused many financial "difficulties". Despite the fact that everything seemed healthy, market was mature and energy firms were still investing in new markets, financial markets suddenly dropped. Even though financial crisis started about three years ago in USA - summer 2007 -, only a few companies tried to secure their exposures. Therefore the unexpected decrease in markets could not be avoided into this turbulent economic environment.

Firms could protect their position with risk management tools. There are many 
studies that refer to risk management and its benefits to the companies which use hedging tools against their risk exposure. Previous studies regarding risk management, such as Allayannis and Weston (2001) who examined the relationship between the usage of foreign currency derivatives and firms' value, concluded that there is a positive relationship between them and derivatives help firms to add financial value significantly. On the other hand, Jin and Jorion (2006) found that oil and gas companies' value in US have no positive impact by using derivatives. The benefit they gain is that their stocks do not follow oil's and gases price volatility. Carter et al. (2004) disclosed that hedging creates firm value on US airline industry.

Bartram et al. (2003) investigated the usage of derivatives in financial and non financial US firms and found that hedging is a process that significantly adds firm value. Guay and Kothari (2003) disclosed that firms spend only a small amount for hedging compared to their financial value and this cannot be a variable which influences firms' value significantly as there are too many proxies that might have greater impact than derivatives. Kenourgios et al. (2008) estimated optimal hedge ratios and examined the hedging effectiveness of the S\&P 500 index using alternative models, both constant and time-varying. Their findings suggest that in terms of risk reduction the error correction model is the appropriate method for estimating optimal hedge ratios since provides better results than the conventional OLS method, the ECM with GARCH errors, the GARCH model, and the EGARCH $(1,1)$ model. Also, the S\&P 500 stock index futures contract is an effective tool for hedging risk.

Lessard (1990), Froot et al. (1993) found that firms using derivatives reduce variation in earnings and cash flows. El-Masry (2006), also, found that UK non financial companies use derivatives in order to manage the volatility and ensure good cash flow levels. Casey (2001) highlights the fact that investment, finance and hedging strategies should go hand in hand.

Furthermore, Gay and Nam (1998) agree with previous studies (Nance et al., 1993 and Froot et al., 1993) which outlined that derivatives use increases while liquidity increases and the opposite. However, Nguyen and Faff (2002) argue with their findings. Kavussanos and Visvikis (2006b) confirmed that risk management in shipping and shipping derivatives help ship-owners and charterers stabilize their income and their costs.

Lien (2010) compared the hedging effectiveness of the conventional hedge ratio and time-varying conditional hedge ratios and proved that that, in large sample 
cases, the conventional hedge ratio provides the best performance. Lien and Yang (2008) evaluated different hedging strategies for aluminum and copper futures contracts traded at Shanghai Futures Exchange and he suggested that the basis has asymmetric effects and optimal hedging strategy constructed from the asymmetric BFIGARCH model tends to produce the best in-sample and out-of-sample hedging performance. In addition, Leon Li (2009) indicated that the out-of-sample performance of the MVSWARCH-based hedge ratio is statistically marginal when investors hold a well-diversified market portfolio as their spot position and tranquil periods are experienced.

Liu and Parlour (2009) showed that access to financial markets makes firms bid more aggressively, hedging increases the variance of bids and makes firm values more dispersed, the covariance of internal capital changes with the risk factor is more negative, the higher the correlation of the hedging instrument with the risk factor. Zanotti et al. (2010) examined hedging policies implemented through different hedge ratios estimation and his findings supported that the choice of the hedge ratio estimation model is central on determining the effectiveness of futures hedging to reduce the portfolio volatility.

Regarding energy market, Lookman (2003) examined derivatives' impact on oil and gas exploration and production firms. His findings prove that hedging primary risks influence firms' value negatively because they put limits in firms' production. On the contrary, he found that firms get a premium when they hedge their secondary risks. Chang et al. (2010) undertook eight hedging models to investigate hedging effectiveness of different price scenarios in energy futures markets. Some confirmed that hedging effectiveness is higher in "bull markets than in "bear markets, both for crude oil and gasoline futures. Also, the ranking different hedging models' hedging effectiveness is not parallel in different price patterns across futures contracts which mean that investors should adjust their hedging strategies accordingly.

Alizadeh et al. (2008) estimated constant and dynamic hedge ratios in the New York Mercantile Exchange oil futures markets and examined their hedging performance. In and out-of-sample tests indicated that state dependent hedge ratios are able to provide significant reduction in portfolio risk. Cotter and Hanly (2010) applied a GARCH-M model to estimate a time-varying measure of risk aversion that is based on the observed risk preferences of energy hedging market participants. The resulting estimates are applied to derive explicit risk aversion based optimal hedge strategies for both short and long hedgers. When they implemented the out-of- 
sample, the risk aversion based hedges differ significantly from simpler OLS hedges. However, when they implemented the in-sample, risk aversion hedges for short hedgers outperform the OLS hedge ratio in a utility based comparison.

Moreover, Giofre (2009) investigated the role of information asymmetries and inflation hedging in shaping international equity portfolios and confirmed - in a multinational setting - Cooper and Kaplanis (1994) result of no inflation hedging motive driving investors' behavior and find evidence of a crucial role for financial market development and trade linkages. Finally, Lai et al. (2009) employed copula methodologies and DCC-Garch and concluded that hedge ratios constructed by a Gaussian or Mixture copula are the best-performed in variance reduction for all markets except Japan and Singapore, and provide close to the best returns on a hedging portfolio over the sample period.

\section{Data and Methodology}

The sample of our study consists of energy firms which are trading in various markets and distributed all over the world. Companies' selection become taking into consideration their area diversification, so as to get a better view for the market that does not only represent a specific area, which can be influenced individually from accidental factors.

Our sample is constituted by fifty energy enterprises. Data selected from DataStream and firms' websites. This study's data are from January $1^{\text {st }} 2007$ till December $31^{\text {st }} 2009$. The period that we examine includes quarterly observations, in order to check the hedging efficiency during last years' crisis.

Sample is divided according to whether firms use derivatives or not. Firms' financial statements state if they use derivatives or not as well as derivatives transactions' volume. Even though derivatives are not only hedging tools but also a speculation vehicle, we adopt their fundamental meaning.

The variable we use in order to measure firms' value is Tobin's $Q$. This equation is defined as the ratio of the firm market value to the replacement cost of its assets. If Tobin's Q exceeds unit then firm's value is higher than every other replacement cost. Literature provides many different definitions of Tobin's Q, but we adopt the Market price to Book value $(M V / B V)$ as the proxy of firms' value.

Taking into consideration that we need to adopt the most appropriate methodology, we run the Haussmann test. Results led us to apply the fixed effects analysis which is expected to give us the most consistent results. 
In order to draw the requested results, Ordinary Least Squares (OLS) regression is used. OLS is a method to analyze panel data and used to several previous studies (Chung and Pruit, 1994; Choudhry, 2000; Allayannis and Weston, 2001; Anderson et al., 2004; Rao et al., 2004; Matzler et al., 2005; Mittal et al., 2005). Our model is as follows:

$$
\operatorname{Ln}(\text { Tobin's } Q)=\alpha+\beta \text { hedge }+\gamma X+\varepsilon
$$

where Tobin's $\mathrm{Q}$ is the proxy for firm value, hedge is the hedging dummy, $X$ is the number of control variables and $\varepsilon$ is the error term. We use logarithms to control the skewness. The independent variables we use are firms' return on assets $(R O A)$ and firms' net debts $(N D)$ and the dependent variable is $M V / B V$.

\section{Empirical Results}

First, we investigate for stationarity using the Augmented Dickey Fuller (ADF) and Phillips-Perron (PP) tests. Results determine that there is no stationarity. Several diagnostic tests were carried out like Breusch-Godfrey test for higher order autocorrelation and White test for heteroskedasticity.

In this research we examine hedging effectiveness in energy market. The evidence from our sample indicates that the results produce 51\% premium on energy firms' value. If examined period referred to "normal" economic conditions, this premium might be lower. Financial uncertainty and firms' inability to control their market value stable during last year's turbulent economic situation are the main reasons which keep this premium high.

Tobin's Q methodology lead to important findings and research's results indicate that energy firms can take advantage and produce better results during unexpected economic facts such as financial crises. Hedging importance is big and its usage essential for all firms. A company is considered a hedger when it uses any kind of derivative contract for risk management purposes and in this case the hedge dummy takes the value of 1 . In this sample only $32 \%$ of them use derivatives during the examined period. Of course energy is a fundamental good and not a simple service. Demand is less affected than other sectors' products or services such as automotive sector or tourism. Huge automotive groups already had financial problems already and sales decreased a lot.

Table 1. contains the summary statistics of our sample as well as of our sub- 
Table 1. Summary Statistics

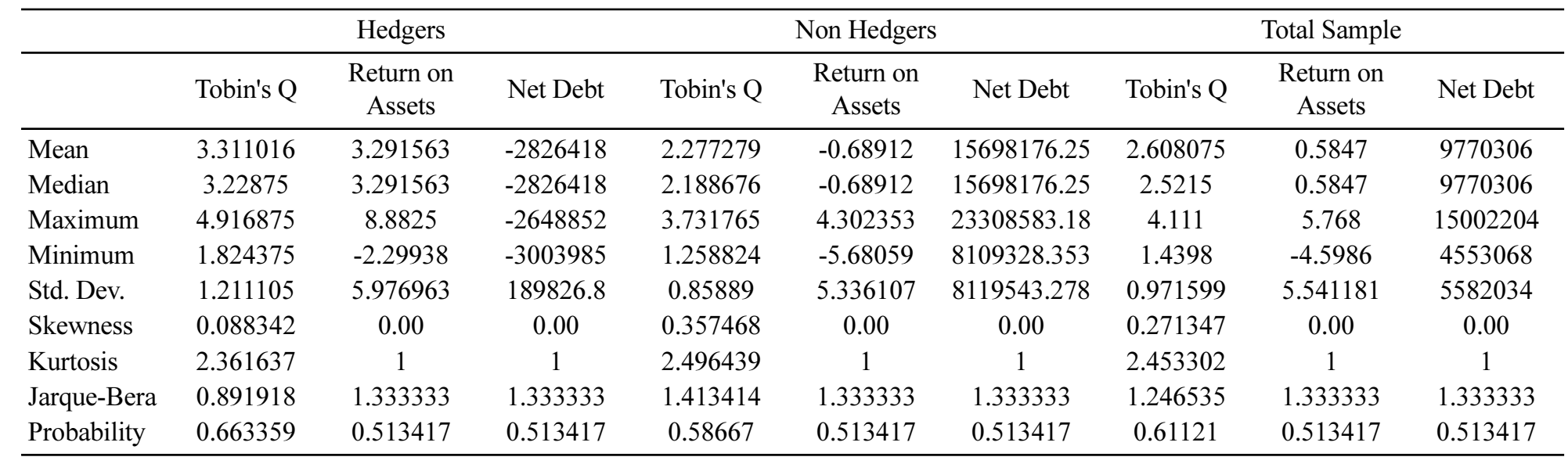


samples. The mean value of Tobin's $Q$ in the whole sample is 2.6 which is higher than 2.52 (median value). So, there is a right skewed distribution and a more symmetric distribution is needed. The natural logarithm of Tobin's Q is adopted in order to get a symmetric distribution. Regarding the subsamples, the mean value is 3.31 for hedgers and 2.28 for non hedgers. In both subsamples the mean is greater than the median which means that in both cases there is a right skewed distribution.

Moreover, above mentioned mean values are greater than the unit and this is a sign that firms generate greater profits than their capabilities. Similar are the results for the subsamples, too.

A brief comparison of the data presented in this table, indicate that firms which use derivatives have lower debts than the one which do not use derivatives. This might be a sign that hedgers protected their position against the hit of financial crisis and try to handle their exposure by using derivatives. Moreover, firms using hedging instruments have better return on assets ratio than the non hedgers.

The results of the empirical analysis are presented in Table 2. The regression's outcome both for hedgers and non hedgers, as well as for all sample consist independent variables' values. Hedge dummy used to measure derivatives' impact on firms' value is also presented.

In Panel A regression's results for firms using hedging tools verify that these firms value higher. Hedge dummy's coefficient is 0.51 and represents a positive and significant impact on firms' value. So, there is a great premium for firms which use any kind of derivatives. Regarding the other two independent variables, return on assets affects them positively, but net debt has almost no impact on their value. Higher debt's level seems not to be a great issue for hedgers as well as for the non hedgers. There is a small difference between samples. Both results for return on assets and net debt are significant which means that analysis gives safe results.

On the other hand, Panel B presents regression's results for firms which do not use any risk management tools. This category's firm value is not affected negatively from net debts, but this is not significant enough in order to get useful results. Return on assets has a significant positive impact to their value.

Panel C provides evidence that total sample firms' net debt impact is slightly positive and significant. So, debts do not influence energy sector much. The main reason is that energy industry is an emerging market, investments are big and it is valued higher from the investors. Finally, return on assets has positive and similar impact like the non hedgers when hedgers get a lower premium from this variable.

Results are in line with many of the previous studies. Hedging as a factor for 
additional firm value found to be significant positive. Similar studies confirm positive impact on firms' value (Allayanis and Weston, 2001; Bartram et al., 2003; Allayannis et al., 2003; Carter et al., 2004; Hagelin et al., 2004). Premiums on firms' value found to be significant and vary between 0.09 and 0.728 .

According to above mentioned authors, independent variables and time horizon vary per study. This study apart from hedging usage, adopts two other basic parameters for firms' value, the net debt and the return on assets. Even though, this is a very simple model as there are many other variables which might influence firms' value, return on assets and net debt give a prompt view for firms' value.

Moreover, many investors focus on safe investments and firms with strong and stable economic background. This study provided evidence that hedging assists companies to grow steadily. Thus, rational investors have a good tool which helps them to decide whether their investment is safe or not. Since investors' behaviour varies, those who prefer to have a low risk portfolio tend to invest in more secured industries such as energy.

Additionally, the aforesaid turbulent economic period led to a restructure of the energy market and interested parties' strategy. The merger and acquisition deal number increased by $24 \%$ compared to 2007 and the 954 deals was a new record. However, the transactions' volume decreased by $41 \%$ to 220 bn USD while in 2007 the total volume was 372.5bn USD (PricewaterhouseCoopers, Power Deals 2008 Annual Review). In 2009 deal volume dropped further to $131 \mathrm{bn}$ USD as well as the number of deals to $10 \%$ in comparison with 2008 (PricewaterhouseCoopers, Power Deals 2008 Annual Review).

Taking into consideration the above change in the number and volume of transactions, energy sector still offers opportunities for investors. Big deals were reduced and big players focused on small deals and key-areas in order to take advantage of the market's turbulence. Thus, investors should consider the new economic environment and take positions as per their expectations and firms' stability and investment policies. So, investors should protect their positions either by hedging themselves or by including firms, which use risk management tools, in their portfolio.

Financial crisis 2008 is a good case study for those who invested without a specific policy. Risk management's usage is crucial for firms' survival. Economy is not expected to get better soon. Optimists believe that year 2010, situation will be corrected, but uncertainty in financial markets remains the main obstacle for energy sector, too. 
Table 2. Regression Results

\begin{tabular}{|c|c|c|c|c|}
\hline \multicolumn{5}{|c|}{ Panel A - Firms Using Derivatives } \\
\hline Variable & Coefficient & Std. Error & t-Statistic & Prob. \\
\hline Return on Assets & 0.045623 & 0.108295 & 1.291742 & 0.1197 \\
\hline Net Debt & 0.0000111 & 0.0000031 & 3.977797 & 0.121373 \\
\hline Hedge Dummy & 0.511222 & 0.056283 & 3.68923 & 0.11968 \\
\hline \multicolumn{5}{|c|}{ (R-squared=0.151546, Adjusted R-squared=0.037294, Log Likelihood=-4.36258) } \\
\hline \multicolumn{5}{|c|}{ Panel B - Firms Not Using Derivatives } \\
\hline Variable & Coefficient & Std. Error & t-Statistic & Prob. \\
\hline Return on Assets & 0.329121 & 0.244473 & 1.981551 & 0.110079 \\
\hline Net Debt & 0.000762 & 0.000342 & 1.446353 & 0.252391 \\
\hline \multicolumn{5}{|c|}{ (R-squared $=0.339466$, Adjusted R-squared $=0.229377$, Log Likelihood $=-1.74676)$} \\
\hline \multicolumn{5}{|c|}{ Panel C - Total Sample } \\
\hline Variable & Coefficient & Std. Error & t-Statistic & Prob. \\
\hline Return on Assets & 0.238402 & 0.200896 & 1.760812 & 0.113158 \\
\hline Net Debt & 0.000532 & 0.000238 & 2.221285 & 0.212284 \\
\hline Hedge Dummy & 0.511222 & 0.056283 & 3.68923 & 0.11968 \\
\hline \multicolumn{5}{|c|}{ (R-squared $=0.279332$, Adjusted R-squared=0.16791, Log Likelihood=-2.58382) } \\
\hline
\end{tabular}

\section{Conclusions}

This research provided evidence that firms which use derivatives to manage their risk exposure add financial value. Using Tobin's Q as a proxy for firms' value, study's findings support a significant positive impact. Furthermore, taking into consideration last months' drop on financial markets, energy sector's decrease is not analogous. Even though non hedgers faced greater problems than the hedgers, energy is still attractive for investors who approach safe and emerging markets. Long run expectations for energy are positive and this can be observed in energy firms' stock value since crisis had lower impact than in other sectors. It is interesting to test again the hedging effectiveness in the energy industry, when market has matured, as situation is now changing rapidly and investors still take positions. In this turbulent economic environment, market conditions are against new investments, therefore we would expect energy industry to follow that rule, as well. Despite investors' expectations though, energy's development continues to grow further, mainly due to its dynamism. The need for energy resources secures that investments in energy are going to rise and energy firms will have to follow a more sustainable investment strategy. Energy firms though, are now keen to use 
risk management tools in order to avoid crashes' consequences.

The aforementioned change in energy firms' investment policy should attract researchers to study the hedging effectiveness even further. It would be very interesting to categorize the examination periods and hedging effect on firms' financial stability as follows:

a) Pre-crisis periods: In this case, all interested parties act "logically", the economic environment is normal and markets' fluctuations are less volatile.

b) Crisis periods: The specific periods' volatility is high and investors' panic has a great impact on their decisions and on firms' stock returns. Firms' viability is difficult and we have an extended number of mergers and acquisitions.

c) Post-crisis periods: Volatility is still high and new investments, synergies, mergers and acquisitions change the economic geography. High competition forces market to grow step by step.

The results are going to underline if hedgers survived after the crashes and also, if their risk management strategy gave them the competitive advantage to grow and dominate to their domestic market. Also, the economic geography is a very important subject to investigate and energy is an interesting topic which researchers should consider further. Power markets still offer many investing opportunities as they are a fertile ground for big groups and countries.

Received 1 May 2011, Revised 30 May 2011, Accepted 7 June 2011

\section{References}

Alizadeh, A.H., Nomikos, N.K. and Pouliasis, P.K. (2008), “A Markov regime switching approach for hedging energy commodities", Journal of Banking \& Finance, 32(9), 1970-1983.

Allayannis, G., Weston, J. (2001), "The Use of Foreign Currency Derivatives and Firm Market Value", Review of Financial Studies, 14, 243-276.

Allayannis, G., Lel, U., Miller, D. (2003), "Corporate Governance and the Hedging Premium Around the World", Working Paper, Darden School of Business, University of Virginia, Charlottesville, VA.

Anderson, E.W., Fornell, C., Mazvancheryl, S.K. (2004), "Customer Satisfaction and Shareholder Value", Journal of Marketing, 68, 172-185.

Bartram, S., Brown, G., Fehle, F. (2003), "International Evidence on Financial Derivatives Usage", Working paper, Lancaster University, University of North Carolina, University of South Carolina.

Becker-Blease, J.R., Goldberg, L.G., Kaen, F.R. (2007), "Mergers and Acquisitions as a 
Response to the Deregulation of the Electric Power Industry: Value Creation or Value Destruction?", Journal of Regulatory Economics, 33(1), 21-53.

Carter, D., Rogers, D., Simkins, B. (2004), "Does Fuel Hedging Make Economic Sense? The Case of the US Airline Industry", Working paper, College of Business Administration, Oklahoma State University, Stillwater.

Casey, C. (2001), "Corporate valuation, capital structure and risk management: Astochastic DCF approach", European Journal of Operational Research, 135, 311-325.

Chang, C.Y., Lai, J.Y. and Chuang, I.Y. (2010), "Futures hedging effectiveness under the segmentation of bear/bull energy markets", Energy Economics, 32(2), 442-449.

Choudhry, T. (2000), "Time Varying Distribution and Hedging Effectiveness of Three PacificBasin Stock Futures", Paper Presented at the European Financial Management Association Conference. June, 2000. Athens, Greece.

Chung, K.H., Pruit, S.W. (1994), “A simple approximation of Tobin's q, Financial Management", 23(3), 70-79.

Cooper, I.A., Kaplanis, E. (1994), "Home bias in equity portfolios, inflation hedging and international capital market equilibrium", Review of Financial Studies, 7(1), 45-60.

Cotter, J. and Hanly, J. (2010), "Time-varying risk aversion: An application to energy hedging", Energy Economics, 32(2), 432-441.

El-Masry, A. (2006), "Derivatives use and risk management practices of UK non-financial companies", Managerial Finance, 32(2), 137-159.

Froot, K., Scharfstein, D., Stein, J. (1993), "Risk management: Coordinating corporate investment and financing policies", Journal of Finance, 48(5), 1629-1658.

Giofre, M. (2009), "The role of information asymmetries and inflation hedging in international equity portfolios", Journal of Multinational Financial Management, 19 (4), 237-255.

Gay, G., Nam, J. (1998), “The Underinvestment Problem and Corporate Derivatives Use", Financial Management, 27(4), 53-69.

Guay, W., Kothari, S.P. (2003), "How much do firms hedge with derivatives?", Journal of Financial Economics, 70, 423-462.

Hagelin, N., Holmen, M., Knopf D. J., Pramborg, B. (2004), "Managerial Stock Options and the Hedging Premium", Working paper, Stockholm University, School of Business.

Jin, Y., Jorion, P. (2006), "Firm Value and Hedging: Evidence From U.S. Oil and Gas Producers", Journal of Finance, 61(2), 893-919.

Kavussanos, M., Visvikis, I. (2006a), "Derivatives and Risk Management in Shipping", London: Witherby Publishing Ltd.

Kavussanos, M., Visvikis, I. (2006b), "Shipping Freight Derivatives - A Survey of Recent Evidence", Maritime Policy \& Management, 33(3), 233-255.

Kenourgios, D., Samitas, A., Drosos P. (2008), "Hedge Ratio Estimation and Hedging Effectiveness: The case of the S\&P500 Stock Index Futures Contract", International Journal of Risk Assessment and Management, 9(1/2), 121-134.

Lai, Y.H., Chen, C.W.S. and Gerlach, R. (2009), "Optimal dynamic hedging via copula- 
threshold-GARCH models, Mathematics and Computers in Simulation", 79(8), 2609-2624.

Lessard, D. (1990), "Global competition and corporate finance in the 1990s", Journal of Applied Corporate Finance, 59-72.

Leo Li, M.Y. (2009), "Could the jump diffusion technique enhance the effectiveness of futures hedging models? A reality test", Mathematics and Computers in Simulation, 79(10), 3076-3088.

Lien, D. (2010), "A note on the hedging effectiveness of GARCH Models", International Review of Economics \& Finance, 18(1), 110-112.

Lien, D. and Yang, L. (2008), "Hedging with Chinese metal futures", Global Finance Journal, 19(2), 123-138.

Liu, T. and Parlour, C.A. (2009), "Hedging and competition", Journal of Financial Economics, 94(3), 492-507.

Lookman, A. (2003), "Does Hedging Increase Firm Value? Comparing Premia for Hedging 'Big' versus 'Small' risks”, Working Paper, Carnegie Mellon University.

Matzler, K., Hinterhuber, H.H., Daxer, C., Huber, M. (2005), "The Relationship between Customer Satisfaction and Shareholder Value", Total Quality Management, 16(5), 671-680.

Mittal, V., Anderson, E.W., Sayrak, A., Tadikamalla, P. (2005), "Dual Emphasis and the Long-Term Financial Impact of Customer Satisfaction, Marketing Science", 24(4), 544-555.

Nance, D., Smith, C., Smithson, C. (1993), "On the Determinants of Corporate Hedging", Journal of Finance, 48(1), 267-284.

Nyugen, H., Faff, R. (2002), "On the determinants of derivative usage by Australian firms", Australian Journal of Management, 27, 1-18.

PricewaterhouseCoopers, Power Deals 2008 Annual Review.

PricewaterhouseCoopers, Power Deals 2009 Annual Review.

Rao, V.R., Agarwal, M.K., Dahlhoff, D. (2004), "How is Manifest Branding Strategy related to the Intangible Value of a Corporation?," Journal of Marketing, 68, 126141.

Zanotti, G., Gabbi, G. and Geranio, M. (2010), "Hedging with futures: Efficacy of GARCH correlation models to European electricity markets", 20(2), 135-148. 